\title{
Las estrategias de sostenibilidad: un reto para el Derecho Urbanístico
}

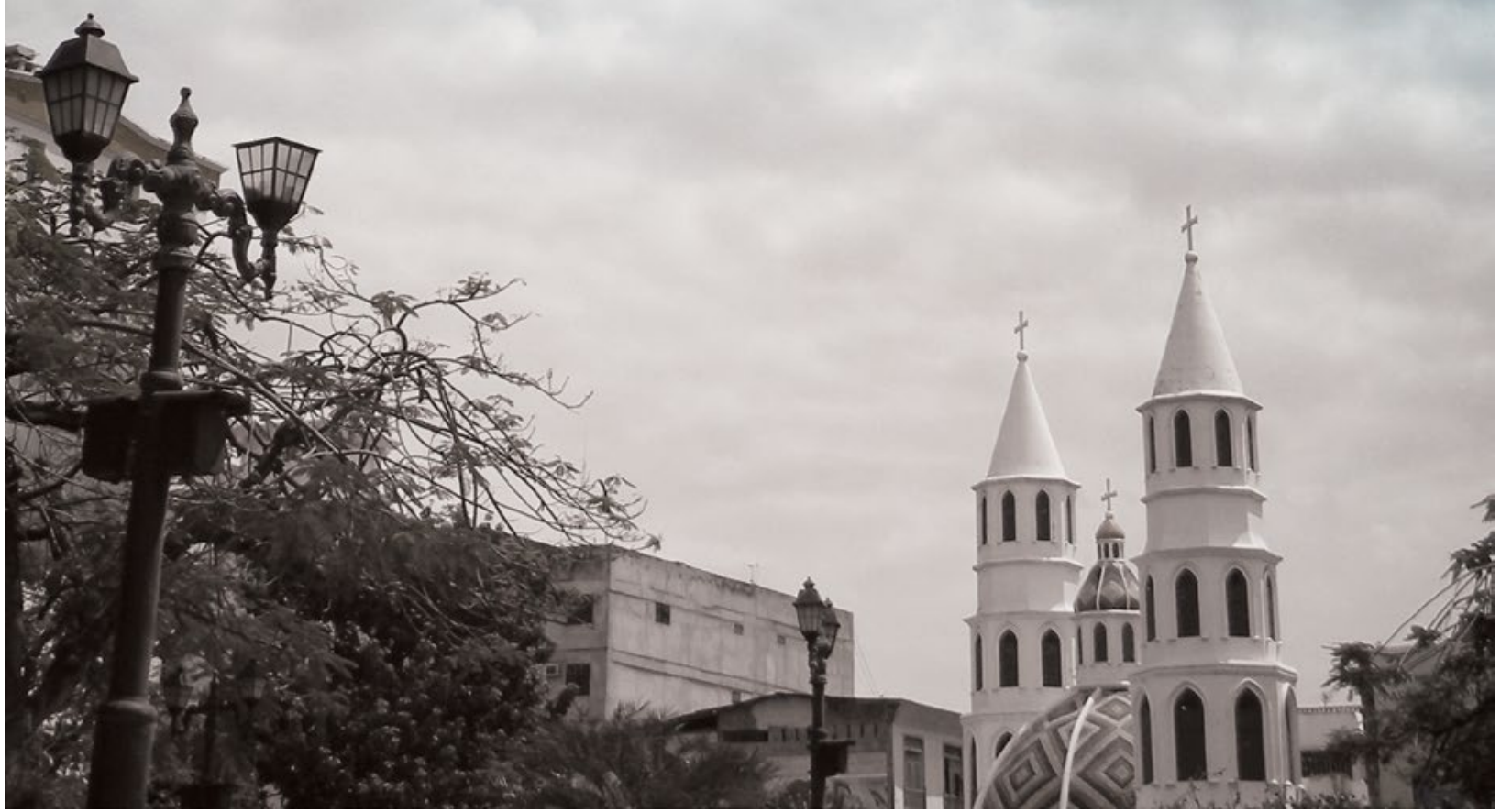




\section{LAS ESTRATEGIAS DE SOSTENIBILIDAD: UN RETO PARA EL DERECHO URBANÍSTICO}

\section{Sustainability strategies: A Challenge for Urban Planning Law}

\section{RESUMEN}

El objetivo del presente estudio es analizar el reto que tiene el Derecho Urbanístico de regular el proceso de urbanización de manera sostenible con la finalidad de elaborar una propuesta de estructura de estrategias y criterios de sostenibilidad que sea una herramienta para evaluar la normativa jurídica urbanística. Para ello, se realizó una investigación documental de diferentes conceptos que sobre el Derecho Urbanístico han formulado tratadistas de varios países. Entre los hallazgos más significativos se destacan que la ciudad sostenible es el principal objetivo de la normativa jurídica urbanística y que ésta se direcciona a tres ámbitos que son: el territorio, la urbanización y la población, a partir de los cuales se propone la estructura de estrategias y criterios de sostenibilidad. Como conclusiones principales se plantea que el Derecho Urbanístico debe ser considerado el principal campo jurídico en el que se construya la nueva visión del crecimiento urbano para convertirlo en desarrollo urbano sostenible y que la estructura propuesta ofrece la posibilidad de establecer auténticas políticas que propicien un desarrollo urbanístico sostenible.

PALABRAS CLAVE: Derecho urbanístico; estrategias de sostenibilidad; planificación urbana; urbanismo

Copyright (c) Revista San Gregorio 2019. ISSN 1390-7247; eISSN: 2528-7907 @

\section{ABSTRACT}

The objective of the present study is to analyze the challenge of Urban Law to regulate the urbanization process in a sustainable way with the purpose of elaborating a proposal of a strategy structure and criteria of sustainability that is a tool to evaluate the legal urban planning. For this purpose, a documentary research was carried out on different concepts that have been formulated by writers from various countries on urban law. Among the most significant findings, it is worth highlighting that the sustainable city is the main objective of urban legal regulations and that it is addressed to three areas: territory, urbanization and population, from which the structure of strategies and sustainability criteria. The main conclusions are that Urban Law should be considered as the main legal field in which the new vision of urban growth is built in order to convert it into sustainable urban development and that the proposed structure offers the possibility of establishing genuine policies that favor urban development sustainable development.

KEYWORDS: Urban law; sustainability strategies; urban planning; urbanism.

Copyright (c) Revista San Gregorio 2019. ISSN 1390-7247; eISSN: 2528-7907 @

Jaime Alfredo Alarcón Zambrano

Universidad San Gregorio de Portoviejo. Manabí. Ecuador.

$\sim$
José Jesús Albert MárQuez

U. Universidad de Córdoba. Córdoba. España.

 


\section{INTRODUCCIÓN}

Los procesos desaforados de industrialización y urbanización vividos a lo largo del siglo $\mathrm{XX}$ y en lo que va del presente, han convertido a la ciudad contemporánea en un órgano contaminante, consumidor de recursos y generador de exclusión social, lo que ha afectado el medio ambiente y la calidad de vida.

La problemática descrita ha motivado la ejecución de muchos estudios; sin embargo, la mayoría de ellos no consideran, en su justa medida, la intervención del Derecho Urbanístico como la estructura jurídica que respalda al urbanismo sostenible necesario para cambiar la situación descrita, que se relaciona directamente con la vida humana.

Las políticas urbanísticas sostenibles se desarrollan a través de instrumentos normativos que se articulan a través del Derecho Urbanístico mediante leyes, reglamentos, planes, y ordenanzas de urbanización y edificación. Por ello, es importante y pertinente que el conjunto de normas jurídicas urbanísticas sea el marco legal que acoja las políticas sostenibles mediante una estructura de estrategias orientada a lograr modelos de desarrollo sostenible.

La presente investigación que tiene como finalidad proponer una estructura de estrategias y criterios de sostenibilidad aplicable al Derecho Urbanístico, se justifica porque a través de la propuesta se trata de coadyuvar a lograr el desarrollo de ciudades sostenibles orientadas a mejorar la calidad de vida de los seres humanos.

\section{METODOLOGÍA}

La presente investigación es de tipo cualitativa y toma de referencia un análisis descriptivo bibliográfico relacionado con los con- ceptos de Derecho Urbanístico, para elaborar una propuesta de estructura de estrategias de sostenibilidad aplicable a dicha normativa jurídica. Se utilizaron preferentemente fuentes primarias como libros y revistas especializadas, la investigación realizada fue una revisión bibliográfica, documental y crítica, de los documentos seleccionados, fundamentada en la experiencia profesional de los autores. Se establece el marco teórico conceptual en base a las palabras clave que son: Urbanismo Sostenible, Derecho Urbanístico, Planificación Urbana y Estrategias de Sostenibilidad, cuyo análisis nos permitió identificar contenidos fundamentales de la temática y contar con las valoraciones teóricas conceptuales para precisar el objetivo y los ámbitos de acción de la normativa jurídica urbanística, a partir de los cuales se identifican síntomas de insostenibilidad y se proponen las correspondientes estrategias y criterios de sostenibilidad aplicables al Derecho Urbanístico.

\section{RESULTADOS Y DISCUSIÓN}

Los resultados y la discusión se sustentan en cuatro subtemas que son: Urbanismo Sostenible, Derecho Urbanístico, Planificación Urbana y Estrategias de Sostenibilidad.

\section{URbanismo Sostenible}

Consideramos que para iniciar el presente trabajo es importante distinguir, al menos a los efectos concretos de este estudio, los conceptos de los vocablos urbano, urbanismo y urbanización.

El vocablo urbano ${ }^{1}$ se deriva de las raíces latinas urbs, urbis y urbanus, que significan ciudad y, por consiguiente, perteneciente a la ciudad; el urbanismo, en cambio, es la ciencia que se encarga de estudiar el ordenamiento de las ciudades en sus ámbitos físico, económico y social; y, la urbanización se refiere al proceso de la implementación de servicios básicos en un terreno o a la transformación de los asentamientos humanos de rurales a urbanos mediante una mayor concentración de población en un determinado espacio territorial (López-Velarde, 2011).

1. Históricamente, el origen del vocablo se relaciona con la ciudad de Ur, de la civilización sumeria, en la baja Mesopotamia, que llego a tener 250.000 habitantes en el año 2500 A.C. (López Velarde, 2011). 
El tratadista español Alberto Martín Gamero, citado por López-Velarde (2011) precisa que el termino urbanismo aparece utilizado por primera vez en el Congreso de Expertos en Planificación, celebrado en Londres en 1910.

Según López (2013) el urbanismo, como política social, surgió en la segunda mitad del siglo XIX en respuesta a los problemas higiénicos y de discriminación de las grandes ciudades. A través de los años ha sido tratado como arte y ciencia, y siempre se lo ha relacionado estrechamente con la planificación de la ciudad. Ha sido definido como la ciencia encargada de ordenar las ciudades, determinando para tal efecto su organización territorial y usos del suelo, los equipamientos urbanos, los sistemas viales, las regulaciones de las edificaciones, la gestión y el control urbano (Castro-Pozo, 2007) ${ }^{2}$.

Autores como Roca (1997) refieren que el urbanismo de la década de los 20 del pasado siglo, es como una "cruza" de ciencia, técnica y arte ${ }^{3}$. Castro-Pozo (2007) considera que siempre está en pleno proceso de desarrollo, debiendo afrontar retos y dificultades provocados por el ensanchamiento territorial y la contaminación ambiental, las migraciones de la población, el diseño de las ciudades modernas, y la conservación de los centros históricos y patrimoniales.

En años recientes y siendo cada vez más frecuente que temas relacionados a la reforma interior de las ciudades, la sostenibilidad ambiental, la eficiencia energética, la lucha contra la especulación, la configuración del derecho a la vivienda como un derecho de nueva generación, entre otros, sean considerados como problemas de interés público que demandan un nuevo urbanismo (Rivero, 2018). Así, el urbanismo, en la exploración de disyuntivas ante la problemática ambiental y en su pretensión de ordenar la ciudad para elevar la calidad de vida de sus habitantes, concibe a la sostenibilidad como un paradigma factible, que permite una visión holística del desarrollo de las urbes porque integra y enlaza tres aspectos fundamentales: el con- trol ambiental, el desarrollo económico y la participación social (Ramírez y Sánchez, 2009) criterio que instaura el urbanismo sostenible constituido por la sostenibilidad medioambiental, económica y social.

La sostenibilidad medioambiental procura que el desarrollo de la ciudad ocasione el mínimo impacto sobre el medio ambiente, que implica disminuir el consumo de recursos y energía, y generar la menor cantidad posible de residuos y emisiones.

La sostenibilidad económica planifica un desarrollo urbano económicamente viable, sin comprometer más recursos que los estrictamente necesarios para proyectos prioritarios que aporten a la economía de la ciudad y sus habitantes.

La sostenibilidad social está dirigida a lograr que los proyectos urbanísticos respondan a las demandas sociales, mejorando la calidad de vida de la población y permitiendo la participación ciudadana.

En ese sentido, Bensusan (2013) afirma que el urbanismo es una auténtica ciencia que procura el arreglo de las ciudades en acuerdo con sus habitantes en el respeto al principio de desarrollo urbano sostenible.

La integración holística de los ejes ambientales, económicos y sociales, permite que las condiciones para mejorar la calidad de vida en la ciudad se sustenten en los aspectos ambientales y de habitabilidad, por lo que se requiere un progreso económico y un desarrollo social.

Por lo tanto, el urbanismo sostenible tiene la tarea de optimizar espacios físicos en la expansión urbana, asignar actividades sociales y económicas, y aplicar nuevos diseños de construcción, que faciliten la compatibilidad entre los servicios ambientales de la ciudad y las acciones humanas propias de la urbe, con la intención de minimizar los impactos negativos de éstas en el entorno y potenciar un justo desarrollo económico y social.

2. En otro sentido, por ejemplo, Tarrago (1987) define al urbanismo como un instrumento que incide sobre el medio ambiente, ya sea con actividades que lo destruyen y otras que lo protegen.

3. De igual manera, García Bellido (1994) y Capel (1999) consideraban la urbanística, entre dos direcciones: el arte y la técnica. 
Los conceptos descritos fijan una evolución del urbanismo con respecto a sus líneas de intervención, que aumentaron en razón de los problemas presentados en las ciudades y que ya no solo se relacionan a la ordenación del territorio, sino que se refieren a los procesos ambientales, económicos y sociales. Evolución conceptual que compartimos porque creemos que el urbanismo debe tener en la actualidad una visión nueva, una perspectiva global e integradora, que no solo se refiera a simples reglas técnicas para la construcción de edificios o el embellecimiento del ornato público, sino que responda a los requerimientos del desarrollo sostenible.

Ahora bien, el proceso de urbanización implica la apropiación, transformación y aprovechamiento del espacio territorial, que sirve de asiento al hombre y su familia para realizar las actividades fundamentales que le permitan una vida digna. Por lo tanto, el momento que el hombre se convierte en sedentario, se desenvuelve en un espacio donde surgen múltiples relaciones sociales, políticas, económicas y culturales. que deben ser reguladas por el Derecho.

Además, siendo el urbanismo en todos sus aspectos una competencia y una responsabilidad irrenunciable de los poderes públicos, requiere de una normativa jurídica para regular y controlar la coexistencia de los intereses en juego que permita una convivencia armónica y un desarrollo sostenible de las urbes (Fernández, 2017).

El vínculo entre hombre y suelo, y las diversas relaciones y problemas que se pueden derivar de los asentamientos humanos dan origen al Derecho Urbanístico (López- Velarde, 2011).

Por consiguiente, a nuestro juicio, el Derecho Urbanístico debe responder al reto que significa regular el proceso de urbanización en base a un urbanismo sostenible.

\section{DeRECho URbanístico}

\subsection{Conceptualización}

El acelerado proceso de urbanización que caracterizó al siglo XX y que continua en el actual, ha ocasionado que la ciencia del derecho responda al reto que significa regular dicha evolución (López-Velarde, 2011).
Así, José Luis Moros, citado por el tratadista español Alberto Martín Gamero, sostiene que "El derecho ha de servir tanto de impulso como de freno a la urbanización" (López-Velarde, 2011, p. 6).

Por ello, Carceller (1997) y Ruiz (1981) instituyen que la función del derecho en materia urbanística se identifica con la existencia de un conjunto de normas y la habilitación de elementos planificadores para que se desarrollen en forma ordenada los procesos de urbanización en las ciudades.

Castro-Pozo (2007) afirma que el Derecho Urbanístico es el conjunto de normas mediante las cuales la administración, en nombre del interés público, y los titulares del derecho de propiedad, en nombre de la defensa de los intereses particulares, deben regular sus acciones con la finalidad de lograr la ordenación del territorio.

Por su parte, Parada (2010) sostiene que el Derecho Urbanístico es el conjunto de normas reguladoras de los procesos de ordenación del territorio y su transformación física a través de la urbanización y la edificación. Por lo tanto, reglamenta potestades públicas muy claras, como la de ordenar el territorio, los procesos de urbanización y la vigilancia sobre la edificación en la ciudad.

Martínez (2011) afirma que el Derecho Urbanístico es el grupo de normas jurídicas, cuya esencia es regular los comportamientos de los habitantes que inciden en el funcionamiento de las ciudades. En este sentido, Rivero (2018) asevera que el nacimiento y la evolución de las ciudades no son productos del azar, sino que son como son porque personas con concretos objetivos, ambiciones e ideologías, las idearon, construyeron y desarrollaron en un determinado momento histórico.

Para López-Velarde (2011) el Derecho Urbanístico es una rama de la ciencia jurídica que se conceptualiza desde la doctrina como el conjunto de normas preferentemente de derecho público que regulan la planeación urbana y la ordenación del suelo en los centros poblados.

En análogo sentido Galvis (2014); Cordero (2015); Rajevic (2017) y Rivero (2018) conciben al Derecho Urbanístico como el conjunto de normas que regulan la planificación terri- 
torial, el uso del suelo urbano y el desarrollo de la ciudad, limitando la propiedad privada y haciendo prevalecer el interés general sobre el particular.

Fernández (2017) mantiene que el Derecho Urbanístico debe dar respuesta a la correcta planificación del uso de nuestro suelo, la misma que debe asegurar, compartiendo con lo expresado en el libro blanco inglés Land ${ }^{4}$, un equilibrio apropiado entre las demandas de suelo, de tal manera que éste se utilice para el beneficio colectivo, más aún que de todos los recursos materiales de que puede disponerse, el suelo es el único que no puede incrementarse.

Por lo descrito, creemos que el Derecho Urbanístico es la disciplina jurídica que regula las competencias de la administración pública y el comportamiento de los ciudadanos, para procurar el racional y armónico uso del suelo y de las actividades que se desarrollan en éste, con el objetivo de lograr ciudades ordenadas, confortables y saludables.

El análisis de la revisión de contenido de los conceptos y principios del Derecho Urbanístico enunciados, establece que lograr una ciudad amigable y sostenible, es el objetivo principal de la normativa jurídica urbanística, y que ésta se encuentra dirigida a tres ámbitos que son: la ordenación del territorio, el proceso de urbanización y la participación ciudadana, que a su vez generan tres elementos que son: el territorio, la urbanización y la población, respectivamente.

El territorio, que es el soporte físico sobre el que funciona la ciudad y que ofrece una variedad de posibilidades de uso; la urbanización, que genera un "metabolismo urbano"5 resultante, con su correspondiente consumo de recursos y producción de residuos; y, la población, que es la que hace un uso específico del soporte físico que dispone, incluyendo su modificación.

\subsection{Principios}

Galvis (2014) sostiene que los principios del Derecho Urbanístico son: la primacía del interés general, la función social y ecológica de la propiedad, y la distribución equitativa de las cargas y beneficios.

La primacía del interés general establece que, en la coordinación que se requiere entre la Administración Pública (sector público) y los titulares del derecho a la propiedad (sector privado), debe prevalecer el beneficio colectivo por sobre el particular.

La función social y ecológica de la propiedad configura la justicia urbana, la cual limita la propiedad privada, y establece mecanismos para garantizar el derecho a la ciudad, y para proteger el medio ambiente.

La distribución equitativa de las cargas y beneficios determina que se deben imponer cargas y sanciones, pero también se deben ofrecer beneficios e incentivos.

Concertamos con los principios explicados porque están dirigidos a construir en la ciudad un futuro socialmente equilibrado, que permita una vida digna con respeto a la naturaleza (Carrión, 2010) y, al goce de las oportunidades sociales y económicas vinculadas a la ubicación de la vivienda y el trabajo (Oszlak, 1991). En fin, son principios axiológicos afines al concepto de la ciudad sostenible.

\subsection{Contenido}

Castro-Pozo (2007) sustenta que el Derecho Urbanístico comprende los aspectos siguientes: la organización administrativa, el régimen del suelo, la gestión urbanística, las normas urbanísticas y la disciplina urbanística.

Por otro lado, Rengifo (2012) establece que el Derecho Urbanístico se compone de tres elementos: la planificación, la gestión y el control; y, Cordero (2015), en cambio, expre-

4. En el Reino Unido, sirvió de anticipo de la que luego sería la Land Community Act 1975: "De todos los recursos materiales de que puede disponerse en estas islas, el suelo es el único que no puede incrementarse”. (Fernández, 2017).

5. El metabolismo urbano es la suma total de los procesos técnicos y socioeconómicos que ocurren en las ciudades, resultando en crecimiento, producción de energía y eliminación de desechos (Kennedy, Cuddihy y Engel-Yan, 2007). 
sa que el contenido del Derecho Urbanístico está constituido por los ámbitos siguientes: la planificación, que se refiere a los planes urbanos; el régimen de la propiedad del suelo, que se relaciona con la zonificación urbana, las clases de suelos y los derechos y deberes de los propietarios; la gestión, que es el conjunto de formas en que se ejecuta la planificación urbana; y, la disciplina, que se identifica con la intervención preventiva de la edificación y uso del suelo, infracciones y sanciones.

Por lo puntualizado, a nuestro criterio, el contenido del Derecho Urbanístico se puede compendiar en tres aspectos: la planificación, la gestión y el control, los mismos que deben ser ejercidos por la Administración Pública en base a la competencia, que doctrinalmente se la puede definir como "la asignación de funciones a un órgano administrativo mediante norma expresa..." (Castro-Pozo, 2007, p. 96). La competencia es uno de los elementos esenciales del acto administrativo y debe ser expresa.

En ese contexto, la competencia urbanística es el reconocimiento jurídico que normalmente atribuye el marco constitucional del Estado a los gobiernos locales, regionales o nacionales. para la aplicación de las normas urbanísticas (Borja, 2011).

\section{Planificación urbana}

El Derecho positivo acoge el vocablo plan precisamente de la mano de las primeras normas urbanísticas, en cuyo texto logra una significación equivalente a la de plano; es decir, una representación gráfica de un espacio físico con características propias y, más concretamente, lo que se desea hacer en el aspecto material con ese espacio de acuerdo a un programa de acciones y proyectos contenido en un plan (Fernández, 2017).

La ordenación del territorio encuentra en los planes de ordenamiento territorial y urbanístico los mejores instrumentos para fijar la distribución de la población y los espacios para las vías públicas, las redes de servicios básicos y la infraestructura para el desarrollo social y económico. De igual manera, la planificación urbana circunscribe los suelos que deben ser protegidos por razones medioambientales, históricas o culturales; y, permite establecer una debida distribución de los espacios arquitectónicos del equipamiento urbano conformado por salud, educación, recreación, comercio y transporte público.

Por ello, respecto de lo indicado, coincidimos con Vegara y De Las Rivas (2004) cuando aseveran que el urbanismo moderno no puede concebirse sin la idea de un plan; y, con Rincón (2012) cuando refiere que la planificación urbana posibilita que se tenga un panorama general de la ciudad que anhelamos para lograr un espacio de convivencia acorde con la dignidad humana.

Por su parte, Calvo (2002) destaca que hay que planificar ciudades más sostenibles, mediante planes eficaces. Por ello, creemos que los planes urbanísticos deben avizorar la ciudad futura, con objetivos y políticas, que sirvan de orientación para que las autoridades, en representación de la población, planifiquen, gestionen y controlen el uso del suelo para un desarrollo sostenible.

Además, la planificación urbana es el instrumento técnico que coadyuva a que las ciudades se ordenen territorialmente y puedan ser dotadas de servicios públicos, garantiza que los costos y beneficios de la urbanización sean distribuidos equitativamente, y asegura que sean sostenibles y resilientes ante peligros sociales y naturales (Silva, 2017).

Los planes de ordenamiento territorial y urbanísticos se constituyen, por lo tanto, en los soportes de la planificación urbana y las normas jurídicas del Derecho Urbanístico. Se los puede considerar como herramientas complejas, de las que depende en gran medida el mejoramiento de los índices de la calidad de vida (Rincón, 2012), criterio que apoyamos porque son los instrumentos mediante los cuales se delimita la expansión de la ciudad y se asigna el suelo de protección para preservar espacios naturales vitales con la finalidad de disminuir los impactos negativos de la actividad humana en la naturaleza.

Ahora bien, a pesar que en la actualidad la planeación urbana ya no solo debe estar orientada hacia la zonificación del territorio bajo las premisas de seguridad y funcionalidad, en razón de las externalidades negativas que puede generar esta manera de ordenar el territorio, sino que debe direccionarse a la diversidad para alcanzar la sustentabilidad de áreas urbanas, a través de la mezcla de usos del suelo y la multiplicidad de sus usuarios 
(Mendiola, 2017), consideramos que la planificación urbana sigue siendo necesaria, inclusive, para la implantación de este nuevo enfoque urbano.

\section{Estrategias DE SOSTENibilidAd}

El tema de la sostenibilidad continua vigente y la razón de ello probablemente haya que investigarla en una sensación general, entre los actores políticos, los técnicos y la población en general, de que ciertas deficiencias ambientales y sociales, lejos de reducirse con el desarrollo económico, se han visto intensificadas. Sin embargo, una vez que se supera este nivel mínimo de sensaciones, desaparece cualquier espacio de consenso, no existe acuerdo sobre las causas ni sobre las soluciones a adoptar para superar estas deficiencias; de hecho, incluso falta un acuerdo sobre el auténtico alcance o gravedad de los síntomas (Fariña y Naredo, 2010). El resultado es que se han acogido una serie de expresiones, como "desarrollo sostenible" o "sostenibilidad", que pretenden albergar la solución a todos los problemas sin que en la mayoría de los casos se llegue a definir su contenido sustantivo.

Por ello, pensamos que en la medida en que se identifica la sostenibilidad con la solución, resulta mucho más adecuado y conveniente comenzar por describir y caracterizar el problema, esto es, la insostenibilidad actual. De ahí que es necesario identificar los principales síntomas de insostenibilidad que se observan en los ámbitos de actuación de la normativa del Derecho Urbanístico, que, como ya hemos analizado, son: la ordenación del territorio (el territorio), el proceso de urbanización (la urbanización) y la participación ciudadana (la población). Al respecto y desde nuestra perspectiva, se identifican los siguientes:

En el territorio:

-Desperdicio del capital natural y construido. -Procesos de exclusión económica y social, asociados al acceso diferencial a los recursos y a un medio ambiente saludable.

En la urbanización:

-Procesos de contaminación ambiental

-Consumo de recursos por encima de su tasa de reposición.

-Producción de residuos por encima de la capacidad natural de absorción.
En la población:

-Distanciamiento de la población de los procesos de toma de decisiones.

Por otro lado, si el Derecho Urbanístico es el conjunto de normas jurídicas cuyo propósito radica en regular las conductas de los seres humanos que inciden en el funcionamiento de las ciudades, para la adecuada organización de su territorio y la correcta operación de los servicios públicos, con la finalidad de otorgar a sus moradores el hábitat requerido por la dignidad humana (Martínez, 2011) es indispensable que esas normas jurídicas consideren estrategias y criterios de sostenibilidad para que puedan cumplir con sus objetivo y principios de promover ciudades dignas, habitables, productivas y sustentables y que a la vez permitan evaluarlas para medir su nivel de cumplimiento.

En ese sentido, creemos que las estrategias de sostenibilidad que se puedan plantear para neutralizar los síntomas de insostenibilidad descritos, deben originarse en estos últimos, considerar los ejes del urbanismo sostenible -social, económico y medioambiental- y tener una aproximación a la esencia conceptual del Derecho Urbanístico. Por ello, deben estar comprendidas en los documentos de esta normativa jurídica mediante una estructura de estrategias y criterios que esté relacionada, precisamente, con el territorio, la urbanización y la población, que son los tres elementos que se derivan de los conceptos analizados anteriormente.

Por lo tanto, en concordancia con los síntomas de insostenibilidad y fundamentados en los argumentos explicados, pasamos a proponer, conforme a nuestro criterio, las estrategias de sostenibilidad siguientes:

En el territorio:

- Conservar, recuperar y regenerar el capital natural y construido.

- Reforzar y recuperar los espacios comunes de convivencia, reduciendo la segregación social y económica.

En la urbanización:

- Reducir la contaminación.

- Reducir el consumo de recursos naturales.

- Reducir la producción de residuos. 
En la población:

- Fomentar la participación ciudadana en los procesos de toma de decisiones.

Posteriormente y con el fin de completar la estructura de las estrategias propuestas, se establecen los criterios de sostenibilidad que permiten contar con una herramienta de evaluación aplicable al Derecho Urbanístico. A nuestro juicio, serían los siguientes:

a.) Criterios del entorno de la ciudad.

- Preservar, mantener y proteger el capital natural.

b.) Criterios del ámbito urbano.

- Definir una estructura y un modelo urbano sostenible;

- Fomentar un uso más sostenible del patrimonio edificado;

- Fomentar la diversidad, calidad y versatilidad de los espacios públicos urbanos;

- Accesibilidad a los elementos equipamiento urbano; $y$,

- Favorecer el acceso a las zonas verdes.

c.) Criterios de transporte.

- Reducir distancias;

- Potenciar los medios de transporte no motorizados; $y$,

- Motivar el transporte público.

d.) Criterios de recursos.

- Optimizar y reducir el consumo de energía; y,

- Optimizar y reducir el consumo del agua.

e.) Criterios de residuos.

- Reducir los residuos; y,

- Gestionar los residuos para reducir su impacto.

f.) Criterios de cohesión social.

- Favorecer la cohesión del tejido social e impedir la exclusión; y,

- Fomentar la diversidad urbana ${ }^{6}$. g.) Criterios de gobernanza 7 .

- Fomentar la transparencia administrativa;

- Favorecer la formación de los ciudadanos Motivar y permitir la participación social en el planeamiento.

Los criterios de sostenibilidad están relacionados con las estrategias que hemos propuesto, y con los tres elementos generados del análisis conceptual del Derecho Urbanístico, que son: el territorio, la urbanización y la población. Los criterios de los literales a.) y b.) se relacionan al territorio; los descritos en los literales c.), d.) y e.) se corresponden con la urbanización; y, los puntualizados en los literales f.) y g.) pertenecen a la población.

Los criterios están redactados de forma que puedan reconvertirse, de forma directa, en un cuestionario de evaluación aplicable a las leyes, reglamentos, planes y proyectos, que constituyen la normativa jurídica urbanística.

Por ejemplo, con el criterio "Preservar, mantener y proteger el capital natural", pueden plantearse las preguntas siguientes:

- ¿Tiene en cuenta la ley "X" la necesidad o conveniencia de preservar, mantener y proteger el capital natural?

- ¿Regula el reglamento "X" los estándares mínimos para preservar, mantener y proteger el capital natural?

- ¿Establece el plan "X" proyectos para preservar, mantener y proteger el capital natural?

- ¿Ha incorporado el Informe " $\mathrm{X}$ " medidas correctoras para, mantener y proteger el capital natural?

A esta estructura se pueden incorporar otros subcriterios alternativos o complementarios de acuerdo a las condiciones específicas del lugar y que éstos puedan evaluarse en función de su adecuación a las estrategias de sostenibilidad.

6. La diversidad urbana, en el contexto del Desarrollo Urbano Sostenible y conforme a la noción de ciudad como sistema complejo, es la mezcla de usos de suelo (ocupación) y la multiplicidad de sus habitantes-usuarios (ocupantes) en un determinado territorio (Mendiola, 2017).

7. La gobernanza es el conjunto de mecanismos de articulación y negociación entre actores públicos, sociales y económicos para la implementación de políticas de cohesión social y construcción de una visión compartida del territorio (Michelini, 2010). 
La estructura de estrategias y criterios de sostenibilidad propuesta consta en el Cuadro No. 1 (Ver en Anexo).

\section{CONCLUSIONES}

- La grave problemática urbana y sus efectos sociales, económicos, políticos y ambientales que afectan a la ciudad moderna, ameritan la intervención de un urbanismo sostenible, que comprenda e integre los aspectos sociales, económicos y ecológicos.

- El urbanismo para lograr su finalidad precisa de un equilibrio y de un marco legal que ha de reflejarse en el Derecho Urbanístico, disciplina jurídica que debe regular el crecimiento urbano para convertirlo en un desarrollo urbano sostenible.

- El Derecho Urbanístico debe incluir estrategias y criterios de sostenibilidad para justificar su vigencia y poder cumplir, desde el punto de vista conceptual, con sus principios y objetivo principal que es la ciudad sostenible.

- Los planes de ordenamiento territorial y urbanísticos que configuran la planificación urbana y se constituyen en los soportes del Derecho Urbanístico, son los documentos que deben fundamentarse en estrategias y criterios de sostenibilidad.

- La estructura de estrategias y criterios de sostenibilidad propuesta, es una herramienta de evaluación aplicable al Derecho Urbanístico.

- La aplicación de la estructura propuesta ofrece la posibilidad de establecer auténticas políticas que propicien un desarrollo urbanístico sostenible, mediante la incorporación de las estrategias de sostenibilidad en las normas jurídicas de los cuerpos legales correspondientes, haciéndolas de cumplimiento obligatorio, y cuyo incumplimiento se tipifique como infracción que pueda ser sancionada administrativa, civil o penalmente, según el caso, pudiendo esta estructura ser aplicada en el Ecuador. 


\section{REFERENCIAS BIBLIOGRÁFICAS}

Bensusan, M. D. P. (2013). Planeamiento urbanístico y territorial. En E. Arana (Ed.). Conceptos para el estudio del derecho urbanístico y ambiental en el grado (pp. 3960). Madrid, España: Editorial Tecnos S. A.

Borja, J. (2011). Revolución urbana y derecho a la ciudad. Quito, Ecuador: Editorial Olacchi

Calvo, M. (2006). Sostenibilidad en el urbanismo: una propuesta. Ciudad y Territorio: Estudios Territoriales, 38(147), pp. 61-84.

Capel, H. (1999). Cien años en la construcción de la ciudad. La veu del Carrer, 60(10).

Carceller, A. (1997). Introducción al derecho urbanístico, Madrid, España: Editorial Tecnos S.A.

Carrión, F. (2010). Ciudad, memoria y proyecto. Quito, Ecuador: Editorial Olacchi.

Castro-Pozo, H. (2007). Derecho Urbanístico. Lima, Perú: Editora Jurídica Grijley.

Cordero, E. (2015). Naturaleza, Contenido y Principios del Derecho Urbanístico Chileno. Revista de Derecho. Universidad Católica del Norte. Sección Estudios, 22(2), pp. 93-138.

Fariña, J. y Naredo, J. M. (2010). Libro blanco de la sostenibilidad en el planeamiento urbanístico español. Madrid, España: Ministerio de la Vivienda. Gobierno de España.

Fernández, T.R. (2017). Manual de derecho urbanístico. Madrid, España: Editorial Civitas, S.A.U.

Galvis, F. (2014). Manual de Derecho Urbanístico. Bogotá, Colombia: Editorial Temis.

García-Bellido, J. (1994). Inicios del lenguaje de la disciplina urbanística en Europa y difusión internacional de la 'urbanización'de Cerdà. VV. AA., Tiempo y espacio en el arte. Homenaje al profesor Antonio Bonet, Madrid: Ed. Complutense, 1103.

Kennedy, C., J. Cuddihy, y J. Engel - Yan. (2007) "El cambio en el metabolismo de las ciudades". Journal of Industrial Ecology (mit Press) (Publicado en línea el 11 de mayo de 2007) 11, no. 2, pp. 43-59

López, F. (2013). Introducción al Derecho Urbanístico. Madrid, España: Marcial Pons

López-Velarde, O. (2011). El futuro de la legislación urbana en las entidades federales de México. En S. P. López y J. Fernández (Ed.) Derecho Urbanístico (pp. 3-32). México, México: Editorial del Instituto de Investigaciones Jurídicas de la Universidad Nacional Autónoma de México.

Martínez, J. P. (2011). El Derecho Urbanístico. En S. P. López y J. Fernández (Ed.). Derecho Urbanístico (pp. 33 62). México, México: Editorial del Instituto de Investigaciones Jurídicas de la Universidad Nacional Autónoma de México.
Mendiola, N. (2017). El concepto de la diversidad urbana. En J. A. Montejano y C. A. Caudillo (Ed.) Densidad, Diversidad y Policentrismo: ¿Planeando ciudades más sustentables? (pp. 85-106). México, México: Editorial del Centro de Investigación en Geografia y Geomática "Ing, Jorge L. Tamayo".

Michelini, J. J. (2010). Gobernanza territorial, iniciativas locales y desarrollo urbano: los casos de Getafe y Alcázar de San Juan. Boletín de la asociación de geógrafos españoles, (54), pp. 175-201.

Oszlak, O. (1991). Merecer la Ciudad. Los pobres y el derecho al espacio urbano. Buenos Aires, Argentina: Editorial CEDES.

Parada, R. (2010). Derecho Administrativo III. Bienes Públicos. Derecho Urbanístico. Duodécima Edición. Madrid, España: Marcial Pons, Ediciones Jurídicas y Sociales. S.A.

Rajevic, E. (2017). Derecho y legislación urbanística en Chile. Revista Derecho Administrativo Económico, (04), pp. 527-548.

Ramírez, A. y Sánchez, J. (2009). Enfoques de desarrollo sostenible y urbanismo. Revista Digital Universitaria. 10 de julio de 2009. 10 (7).

Rengifo, M. (2012). El concepto de Derecho Urbano. En J. F. Pinilla y M. Rengifo (Ed.), La ciudad y el derecho. Bogotá, Colombia: Editorial Universidad de los Andes.

Rincón, J. (2012). Planes de Ordenamiento territorial, propiedad y medio ambiente. Bogotá, Colombia: Digiprint Editores EU.

Rivero, J. (2018). Manual Básico de Derecho Urbanístico. Madrid, España: Editorial Tecnos.

Roca, M. Á. (1997). Regeneración y futuro de los centros metropolitanos. Madrid, España: Ayuntamiento de Madrid.

Ruiz, J. F. (1981). Introducción al derecho mexicano: derecho urbanístico, México, México: Universidad Nacional Autónoma de México, UNAM.

Silva, E. (2017). Prólogo. En J. A. Montejano y C. A. Caudillo (Ed.), Densidad, Diversidad y Policentrismo: ¿Planeando ciudades más sustentables? (pp. 9-13). México D.F., México: Editorial del Centro de Investigación en Geografía y Geomática "Ing, Jorge L. Tamayo".

Tarrago, M. (1987). La ciudad y el urbanismo. Manual de gestión municipal democrática. Madrid, España.

Vegara, A., y De Las Rivas, J. (2004). Territorios inteligentes. Madrid, España: Fundación Metrópoli, 
ANEXOS

\begin{tabular}{|c|c|c|c|}
\hline ELEMENTOS & $\begin{array}{l}\text { ESTRATEGIAS DE } \\
\text { SOSTENIBILIDAD }\end{array}$ & $\begin{array}{l}\text { ÁMBITOS DE } \\
\text { ACTUACIÓN }\end{array}$ & CRITERIOS DE SOSTENIBILIDAD \\
\hline \multirow{2}{*}{ TERRITORIO } & $\begin{array}{l}\text { Conservar, recuperar y regenerar } \\
\text { el capital natural y construido. }\end{array}$ & $\begin{array}{l}\text { Entorno de la } \\
\text { ciudad }\end{array}$ & $\begin{array}{l}\text { Preservar, mantener y proteger el } \\
\text { capital natural. }\end{array}$ \\
\hline & $\begin{array}{l}\text { Reforzar y recuperar los espacios } \\
\text { comunes de convivencia, } \\
\text { reduciendo la segregación social } \\
\text { y económica. }\end{array}$ & Urbano & $\begin{array}{l}\text { Definir un modelo sostenible. } \\
\text { Fomentar el uso sostenible del } \\
\text { patrimonio construido. } \\
\text { Fomentar la diversidad del espacio } \\
\text { público. } \\
\text { Accesibilidad al equipamiento } \\
\text { urbano. }\end{array}$ \\
\hline \multirow{3}{*}{ URBANIZACIÓN } & $\begin{array}{l}\text { Reducir la contaminación } \\
\text { ambiental. }\end{array}$ & Transporte & $\begin{array}{l}\text { Reducir distancias. } \\
\text { Potenciar transporte no motorizado. } \\
\text { Motivar el transporte público. }\end{array}$ \\
\hline & $\begin{array}{l}\text { Reducir el consumo de recursos } \\
\text { naturales }\end{array}$ & Recursos & $\begin{array}{l}\text { Optimizar y reducir el consumo de } \\
\text { energia. } \\
\text { Optimizar y reducir el consumo de } \\
\text { agua. }\end{array}$ \\
\hline & $\begin{array}{l}\text { Reducir la producción de } \\
\text { residuos. }\end{array}$ & Residuos & $\begin{array}{l}\text { Reducir los residuos. } \\
\text { Gestionar los residuos para reducir } \\
\text { su impacto. }\end{array}$ \\
\hline \multirow[b]{2}{*}{ POBLACIÓN } & \multirow{2}{*}{$\begin{array}{l}\text { Fomentar la participación } \\
\text { ciudadana en los procesos de } \\
\text { toma de decisiones a todos los } \\
\text { niveles. }\end{array}$} & $\begin{array}{l}\text { Cohesión } \\
\text { social }\end{array}$ & $\begin{array}{l}\text { Favorecer la cohesión del tejido } \\
\text { social. } \\
\text { Fomentar la diversidad urbana. }\end{array}$ \\
\hline & & Gobernanza & $\begin{array}{l}\text { Fomentar la transparencia } \\
\text { administrativa. } \\
\text { Favorecer la formación del } \\
\text { ciudadano. } \\
\text { Motivar y permitir la participación } \\
\text { ciudadana. }\end{array}$ \\
\hline
\end{tabular}

